\title{
Effect of Conditions of Carbon Sorbents Producing from Abies Bark on Their Structure and Sorption Properties
}

\author{
Ivan P. Ivanov, \\ Evgeniya V. Veprikova and Nikolai V. Chesnokov* \\ Institute of Chemistry and Chemical Technology SB RAS \\ FRC "Krasnoyarsk Science Center SB RAS" \\ 50/24 Akademgorodok, Krasnoyarsk, 660036, Russia
}

Received 08.08.2019, received in revised form 11.08.2019, accepted 04.09.2019

\begin{abstract}
The ability of producing of effective carbon sorbents from abies bark with the use of thermal alkaline activation in presence of potassium hydroxide was shown. The effects of ratio of bark to alkaline, and temperature of bark pre-carbonization on the porous structure and sorption properties of the carbon sorbents were studied. It was shown, that the capacity of carbon sorbents on iodine is defined by pores with a width 0,73-1,86 $\mathrm{nm}$, on methylene blue $-0,86-2,95 \mathrm{~nm}$, and on vitamin $B_{12}-\geq 9,31 \mathrm{~nm}$. It was determined, that the carbon sorbent, producing by alkaline activation of product of abies bark carbonization at $400^{\circ} \mathrm{C}$, has a high sorption capacity for studied marker substances. For this sorbent kinetic of iodine, methylene blue and vitamin $B_{12}$ sorption was studied in comparison with the simple of commercial active coal for medical purposes. It was determined, that this sorbent exceeds the commercial sample in sorption of iodine and vitamin $B_{12}$ in 1,5 time, and at sorption of methylene blue - in 1.7 time, and it is characterized by a higher rate constants of their markers sorption.
\end{abstract}

Keywords: abies bark, alkaline activation, carbonization, carbon sorbent, micropores, mesopores, sorption, iodine, methylene blue, vitamin $B_{12}$.

Citation: Ivanov I.P., Veprikova E.V., Chesnokov N.V. Effect of conditions of carbon sorbents producing from abies bark on their structure and sorption properties, J. Sib. Fed. Univ. Chem., 2019, 12(3), 423-433. DOI: 10.17516/1998-2836-0139.

(c) Siberian Federal University. All rights reserved

* Corresponding author E-mail address: veprikova2@mail.ru 


\title{
Влияние условий получения углеродных сорбентов \\ из коры пихты на их структуру \\ и сорбционные свойства
}

\author{
И.П. Иванов, Е.В. Веприкова, Н.В. Чесноков \\ Институт химии и химической технологии СО РАН \\ ФИЦ «Красноярский научный центр СО РАН \\ Россия, 660036, Красноярск, Академгородок, 50/24
}

Представлена возможность получения эффективных углеродных сорбентов из коры пихты с использованием термощелочной активации в присутствии гидроксида калия. Изучено влияние соотношения коры и щелочи, температуры предварительной карбонизации коры пихты на пористую структуру и сорбционные свойства углеродных сорбентов. Показано, что сорбиионная емкость углеродных сорбентов по йоду определяется порами шириной 0,731,86 нм, по метиленовому синему (MC) - порами шириной 0,86-2,95 нм, а по витамину $B_{12}$ порами $\geq 9,31$ нм. Установлено, что углеродный сорбент, полученный щелочной активацией продукта карбонизации коры пихты при $400{ }^{\circ} \mathrm{C}$, характеризуется высокой сорбиионной емкостью по исследованным маркерным веществам. Для этого сорбента изучена кинетика сорбиии йода, метиленового синего и витамина $B_{12}$ в сравнении с образиом промышленного активированного угля медицинского назначения. Установлено, что изучаемый сорбент превосходит образеи сравнения по сорбции йода и витамина $B_{12}$ в 1,5 раза, а по сорбции $M C-8$ 1,7 раза и характеризуется более высокими константами скорости сорбции этих маркеров.

Ключевые слова: кора пихты, щелочная активачия, карбонизация, углеродный сорбент, микропоры, мезопоры, сорбция, йод, метиленовый синий, витамин $B_{12}$.

\section{Введение}

Древесная кора является крупнотоннажным отходом переработки древесины, и на ее долю может приходиться 10-15 \% объема ствола. В рамках рационального природопользования такие отходы служат ценным сырьем для получения различных продуктов с востребованными свойствами, например, пористых углеродных материалов (активных углей), применяемых в процессах разделения и очистки жидких и газообразных сред $[1,2]$.

Перспективным направлением применения активных углей может стать энтеросорбционное удаление токсинов различной природы в медицине и ветеринарии. Несмотря на разнообразие промышленно выпускаемых энтеросорбентов, активные угли подтвердили свою эффективность при отравлениях и патологиях, осложненных интоксикациями [3, 4]. Действие активных углей определяется развитой поверхностью и характером пористой структуры, поэтому высока актуальность разработок способов получения активных углей, содержащих поры разного размера [5-7]. Исследования соответствия размеров пор размерам молекул, моделирующим токсины с разной молекулярной массой (метиленового синего, витамин $\mathrm{B}_{12}$ и др.), и влияния их коли- 
чества и размера на сорбционную емкость активных углей, приведенные в названных работах, показывают их важное научное и практическое значение. Полученные результаты позволяют обоснованно выбирать условия синтеза активных углей, ориентированные на оптимальное соответствие параметров их пористой структуры конкретным задачам энтеросорбции $[8,9]$.

Перспективным способом получения из древесных отходов пористых углеродных материалов, способных регулировать размеры и объем микро- и мезопор в широких пределах, является термохимическая активация в присутствии гидроксида калия $[7,10,11]$. Поскольку структура таких материалов зависит от природы исходного сырья, это необходимо учитывать при выборе условий их получения [11]. Кроме того, привлечение новых отходов биомассы для создания углеродных материалов, которые предполагается использовать в медицине и ветеринарии, требует комплексного изучения взаимосвязи условий получения, характера распределения пор по размерам и их сорбционных свойств.

Цель данной работы состояла в изучении влияния условий получения углеродных сорбентов из коры пихты на параметры их пористой структуры и сорбцию йода, метиленового синего и витамина $\mathrm{B}_{12}$.

\section{Экспериментальная часть}

Сырьем для получения углеродных сорбентов служила воздушно-сухая (влажность 9,5 $\pm 0,5$ мас. \%) измельченная кора пихты фракции менее 2,5 мм.

Получение углеродных сорбентов методом термощелочной активации гидроксидом калия исходной коры и карбонизатов на ее основе проводили со скоростью нагрева $10{ }^{\circ} \mathrm{C} /$ мин до $800{ }^{\circ} \mathrm{C}$ в токе аргона согласно методике [12]. Для исследования сорбционных свойств образцы измельчали до размера частиц менее 0,25 мм.

Уголь активированный (УА-Н), выпускаемый $3 \mathrm{AO}$ «Производственная фармацевтическая компания Обновление» (г. Новосибирск, ЛП-000178) для применения в медицине, был выбран в качестве образца сравнения. Для определения сорбционных свойств УА-Н измельчали до размера частиц менее 0,25 мм и промывали горячей водой от вспомогательных веществ.

Изучение пористой структуры углеродных сорбентов из коры пихты проводили на сорбционном анализаторе ASAP 2029MP-C (Micromeritics, США) методом определения изотерм низкотемпературной адсорбции азота (чистотой 99,999 \%) при температуре 77 К в интервале $\mathrm{P} / \mathrm{P}_{\mathrm{o}}=5 \cdot 10^{-6} \div 0,998$ с высокой степенью разрешения в области объемного заполнения микропор $\mathrm{P} / \mathrm{P}_{\mathrm{o}} \leq 0,01$. Расчет площади удельной поверхности $\left(\mathrm{S}_{\mathrm{BET}}\right)$, объемов микро- $\left(\mathrm{V}_{\mathrm{mi}}\right)$ и мезопор $\left(\mathrm{V}_{\mathrm{me}}\right)$ проводили на основании теории БЭТ с корректировкой интервала $\mathrm{P} / \mathrm{P}_{\mathrm{o}}$ для учета микропор [13-15]. Инкрементальное распределение пор по размеру было рассчитано с помощью метода DFT (density functional theory) [16].

Для определения сорбционной емкости углеродных сорбентов применяли маркерные вещества с разной молекулярной массой: по йоду и метиленовому синему, моделирующих органические вещества с массой до 500 Д; по витамину $\mathrm{B}_{12}$, моделирующему вещества массой 500-1500 Д согласно работе [7].

Кинетику сорбции йода, $\mathrm{MC}$ и витамина $\mathrm{B}_{12}$ изучали, варьируя продолжительность процесса от 5 с до 24 ч. Навеска образца согласно методике [17] составляла 80 мг, объем раствора маркера 10 мл. При изучении кинетики применяли 0,01 \% раствор витамина $\mathrm{B}_{12}$ согласно работе [17].

$$
-425-
$$


Обработку данных по кинетике сорбции йода, МС и витамина $\mathrm{B}_{12}$ и расчет констант скорости процессов проводили по модели псевдопервого порядка [18]:

$$
A_{t}=A_{P}\left(1-e_{1}^{-k t}\right)
$$

где $\mathrm{A}_{\mathrm{t}}$ - сорбция в момент времени $\mathrm{t}, \mathrm{Mг} / \mathrm{\Gamma} ; \mathrm{A}_{\mathrm{P}-}$ равновесная сорбция, мг/г; $\mathrm{t}$ - время, мин; $\mathrm{k}_{1}-$ константы скорости сорбции $\left(\right.$ мин $\left.^{-1}\right)$.

\section{Результаты и обсуждение}

Данные табл. 1 показывают, что термощелочная активация исходной коры пихты при вариации количества $\mathrm{KOH}$, вносимого в реакционную смесь, позволяет получать углеродные сорбенты с развитой удельной поверхностью и пористостью.

В зависимости от условий получения на долю микропор в структуре этих сорбентов при-

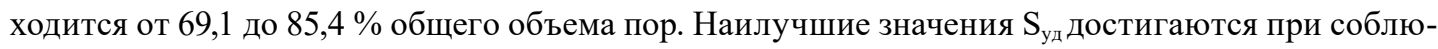
дении соотношения КП:КОН, равном 1:3 (табл. 1).

Варьирование соотношения коры и щелочи показало (рис. 1), что увеличение этого значения от 1:1 до 1:2 приводит к увеличению в структуре КП-2 максимума объемов микропор шириной 0,54 и 0,86 нм, а максимумы для более крупных микропор (1,18 и 1,48 нм) уменьшаются. Одновременно наблюдается уменьшение объема мезопор в структуре этого образца по сравнению с КП-1 - например, пор размера 2,00 и 2,52 нм (рис. 1a).

Увеличение соотношения до 1:3 существенно повышает объемы крупных микропор в структуре КП-3 по сравнению с КП-2 - в 2,3 и 1,9 раза соответственно. При этом для образца КП-3 было отмечено уменьшение объемов микропор размером от 0,46 до 0,68 нм и от 0,86 до 1,00 нм. Последующее повышение соотношения коры и щелочи до 1:4 сопровождается уменьшением объемов пор размером $\geq 1,09$ нм в 1,3 раза относительно КП-3 (рис. 1б). Данные, приведенные на рис. 1 , показывают, что отличительной особенностью углеродного сорбента КП-3 является наличие в его структуре мезопор размером $\geq 9,31$ нм в количестве $0,015 \mathrm{~cm}^{3} /$. Для образцов КП-1 и КП-2 объем пор вышеуказанного размера на порядок меньше $\left(0,002 \mathrm{~cm}^{3} / \Gamma\right)$, а в структуре КП-4 такие поры отсутствуют.

Термощелочная активация карбонизатов из коры пихты, полученных при температуре от 300 до $800{ }^{\circ} \mathrm{C}$, позволяет получать углеродные сорбенты с существенно более развитой пори-

Таблица 1. Параметры пористой структуры углеродных сорбентов из коры пихты (КП), полученных при различном соотношении коры и КОН (КП:КОН)

Table 1. Parameters of the porous structure of carbon sorbents fromabiesbark (КП), producing at different bark to $\mathrm{KOH}$ ratio (КП:КОН)

\begin{tabular}{|c|c|c|c|c|}
\hline $\begin{array}{c}\text { Углеродный } \\
\text { сорбент }\end{array}$ & КП:КОН & $\mathrm{S}_{\text {уд }}, \mathrm{M}^{2} / \Gamma^{*}$ & $\mathrm{~V}_{\mathrm{mi}}, \mathrm{cm}^{3} / \Gamma^{*}$ & $\mathrm{~V}_{\mathrm{me}}, \mathrm{cm}^{3} / \Gamma^{*}$ \\
\hline КП-1 & $1: 1$ & 1063,2 & 0,47 & 0,08 \\
\hline КП-2 & $1: 2$ & 1141,9 & 0,49 & 0,13 \\
\hline КП-3 & $1: 3$ & 1391,5 & 0,56 & 0,25 \\
\hline КП-4 & $1: 4$ & 1389,1 & 0,59 & 0,14 \\
\hline
\end{tabular}

Примечание. Параметры определены по методу БЭТ. 


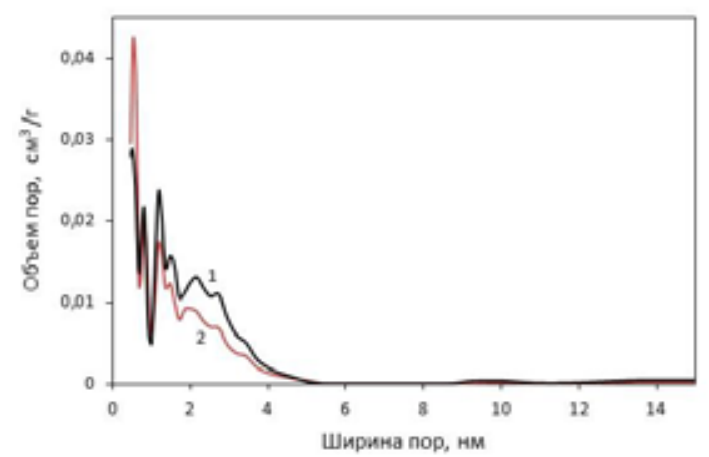

a

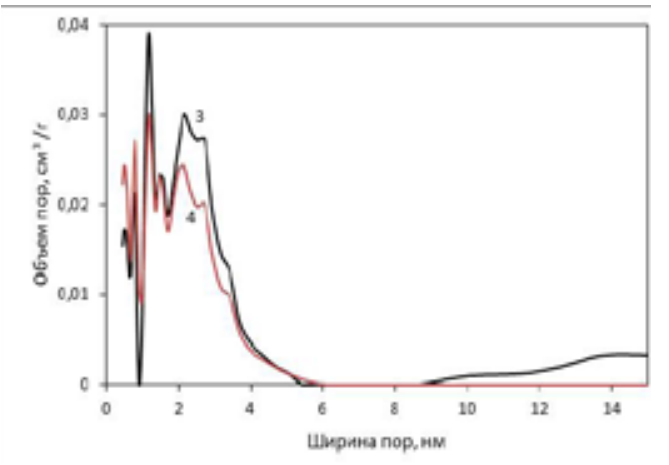

6

Рис. 1. Распределение пор по размерам в углеродных сорбентах из коры пихты (получены методом DFT) в зависимости от соотношения коры и КОН (К:КОН): 1 - КП:КОН=1:1; 2 - КП:КОН=1:2; 3 - КП:КОН=1:3; $4-\mathrm{K}: \mathrm{KOH}=1: 4$

Fig. 1. Pores size distribution in the carbon sorbents from abies bark (obtained by DFT method) in dependence of bark to $\mathrm{KOH}$ ratio (КП:КОН): 1 - КП:КОН=1:1; 2 - КП:КОН=1:2; 3 - КП:КОН=1:3; 4 - КП:КОН=1:4

Таблица 2. Параметры пористой структуры углеродных сорбентов из предварительно карбонизованной коры пихты (ККП)

Table 2. Parameters of the porous structure of carbon sorbents from previously carbonized abies bark (ККП)

\begin{tabular}{|c|c|c|c|c|}
\hline $\begin{array}{c}\text { Углеродный } \\
\text { сорбент }\end{array}$ & $\begin{array}{c}\text { Температура } \\
\text { карбонизации, }{ }^{\circ} \mathrm{C}\end{array}$ & $\mathrm{S}_{\text {уд }}, \mathrm{M}^{2} / \Gamma^{*}$ & $\mathrm{~V}_{\text {mi }}, \mathrm{cm}^{3} / \Gamma^{*}$ & $\mathrm{~V}_{\text {me }}, \mathrm{cm}^{3} / \Gamma^{*}$ \\
\hline ККП-1 & 300 & 1891,7 & 0,84 & 0,08 \\
\hline ККП-2 & 350 & 2048,8 & 0,93 & 0,17 \\
\hline ККП-3 & 400 & 2431,8 & 1,05 & 0,18 \\
\hline ККП-4 & 500 & 1960,9 & 0,86 & 0,10 \\
\hline ККП-5 & 700 & 1122,5 & 0,49 & 0,06 \\
\hline ККП-6 & 800 & 1235,9 & 0,54 & 0,07 \\
\hline
\end{tabular}

Примечание. Параметры определены по методу БЭТ.

стой структурой в сравнении с сорбентами из исходной коры (табл. 1 и 2). На долю микропор в них приходится от 84,5 до 91,3 \% общего объема пор, а максимальный объем мезопор в 1,4 раза меньше по сравнению с сорбентами, полученными из некарбонизованной коры.

Закономерности изменения распределения пор по размерам в структуре углеродных сорбентов, наблюдаемых при варьировании температуры предварительной карбонизации коры пихты, иллюстрирует рис. 2.

Варьирование температуры карбонизации от 300 до $400{ }^{\circ} \mathrm{C}$ приводит к увеличению в структуре углеродных сорбентов на их основе максимумов объемов микропор шириной 1,18 и 1,59 нм. Существенно увеличивается и объем пор $>2,00$ нм. В сорбентах на основе карбонизатов, полученных при 350 и $400{ }^{\circ} \mathrm{C}$, отмечено увеличение мезопор до 5,45-5,88 нм. Структуру ККП-2 отличает и увеличение объема пор размером 0,54 нм (рис. $2 a$ ).

Повышение температуры до $500{ }^{\circ} \mathrm{C}$ приводит к увеличению в структуре углеродного сорбента объема пор размером $\leq 0,64$ нм и уменьшению объемов пор от 0,68 до 4,66 нм. Для сор-

$$
-427-
$$




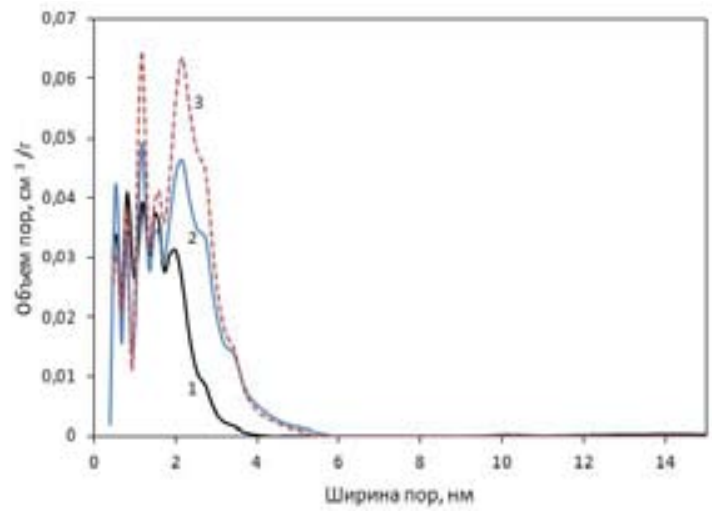

a

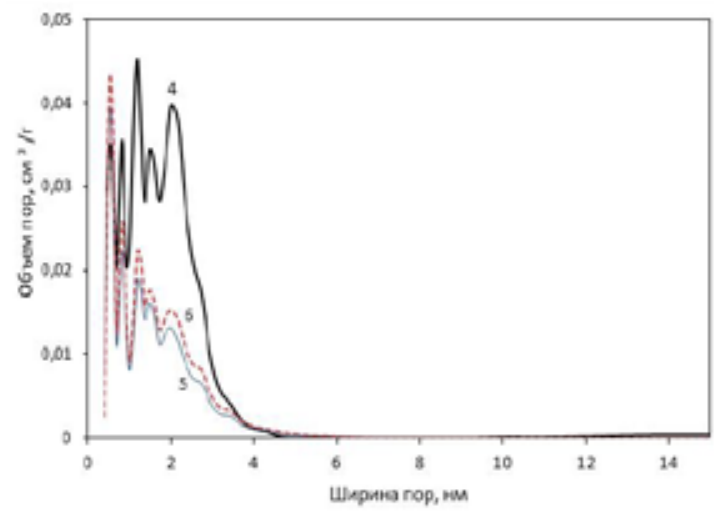

6

Рис. 2 Распределение пор по размерам в углеродных сорбентах из коры пихты (получены методом DFT) в зависимости от температуры получения исходных карбонизатов: $1-300{ }^{\circ} \mathrm{C} ; 2-350{ }^{\circ} \mathrm{C} ; 3-400{ }^{\circ} \mathrm{C}$; $4-500{ }^{\circ} \mathrm{C} ; 5-700{ }^{\circ} \mathrm{C} ; 6-800{ }^{\circ} \mathrm{C}$

Fig. 2. Pores size distribution in the sorbents from abies bark (obtained by DFT method) in dependence of temperature of initialcarbonates producing: $1-300{ }^{\circ} \mathrm{C} ; 2-350{ }^{\circ} \mathrm{C} ; 3-400{ }^{\circ} \mathrm{C} ; 4-500{ }^{\circ} \mathrm{C} ; 5-700{ }^{\circ} \mathrm{C} ; 6-$ $800{ }^{\circ} \mathrm{C}$.

бента на основе этого карбонизата характерно появление в его структуре мезопор размером $\geq 10,06$ нм, объем которых составляет $0,25^{x} 10^{-3} \mathrm{~cm}^{3} /$ г. Применение более высоких температур карбонизации коры пихты $\left(700\right.$ и $\left.800{ }^{\circ} \mathrm{C}\right)$ позитивно влияет только на объем микропор размером 0,54 нм. В целом наблюдается существенное уменьшение объемов микро- и мезопор разного размера и отсутствие пор $>7,39$ нм (рис. 26).

Объемы пор, доступных по своим размерам молекулам маркерных веществ, были рассчитаны по данным о распределении пор разного размера с применением метода DFT. Для молекул йода, $\mathrm{MC}$ и витамина $\mathrm{B}_{12}$ это поры шириной $\geq 0,73, \geq 0,86$ и $\geq 1,48$ нм соответственно (табл. 3 ). Минимальный размер пор, доступных для сорбции применяемых маркеров, был определен с учетом размеров молекул МС ( 0,47 х 0,84 x 1,60 нм [19]), йода ( 0,48 x 0,73 x 0,98 нм [19]) и витамина $\mathrm{B}_{12}(1,41 \times 1,83 \times 1,14$ нм [20]).

Было выявлено, что сорбция йода углеродными сорбентами из коры пихты хорошо согласуется с изменением в их структуре объема микропор размером 0,73-1,86 нм с максимумом для образца ККП-3, в структуре которого на долю таких пор приходится 67,2 \% общего объема микропор. Образец содержит также максимальное количество пор размером 2,0-2,95 нм, которые способны обеспечить транспорт молекул маркера к центрам сорбции. Однако сравнение свойств образцов ККП-2 и ККП-4, отличающихся по объему мезопор указанного размера и пор >3,18 нм, но содержащих одинаковые объемы микропор 0,73-1,86 нм, свидетельствует об определяющей роли последних в процессе сорбции йода. Следует отметить, что углеродные сорбенты из коры пихты независимо от условий получения превосходят образец сравнения (УА-Н) по сорбции йода 2,5 раза (табл. 3).

По сорбции МС углеродные сорбенты КП-1, КП-2, ККП-5 и ККП-6 мало отличаются друг от друга вследствие близких значений объемов пор 0,86 - 1,86 нм в их структуре. При этом, несмотря на более развитую пористую структуру, эти сорбенты по сорбции МС кореллируют 
Таблица 3. Содержание микро- и мезопор разного размера в углеродных сорбентах из коры пихты

Table 3. The contentof micro and mezopores of different size in carbon sorbents from abies bark

\begin{tabular}{|c|c|c|c|c|c|c|c|c|}
\hline \multirow{2}{*}{$\begin{array}{c}\text { Углеродный } \\
\text { сорбент }\end{array}$} & \multicolumn{5}{|c|}{ Объем пор различного размера (нм), $\mathrm{cm}^{3} / \Gamma$} & \multicolumn{3}{|c|}{ Сорбция, $\mathrm{A}^{\text {мах }}$} \\
\hline & $0,73-1,86$ & $0,86-1,86$ & $1,48-1,86$ & $2,00-2,95$ & $3,18-5,88$ & $\mathrm{~J}_{2}, \Gamma / \Gamma$ & $\mathrm{MC}, \mathrm{M \Gamma} / \Gamma$ & $\mathrm{B}_{12}, \mathrm{M \Gamma} / \Gamma^{* *}$ \\
\hline КП-1 & 0,19 & 0,15 & 0,05 & 0,07 & 0,02 & 1,63 & 289,9 & 38,3 \\
\hline КП-2 & 0,15 & 0,13 & 0,04 & 0,05 & 0,01 & 1,61 & 245,3 & 25,8 \\
\hline КП-3 & 0,24 & 0,22 & 0,09 & 0,16 & 0,05 & 1,92 & 447,8 & 141,5 \\
\hline КП-4 & 0,25 & 0,22 & 0,08 & 0,12 & 0,04 & 1,73 & 429,3 & 44,2 \\
\hline ККП-1 & 0,41 & 0,36 & 0,13 & 0,10 & 0,01 & 2,52 & 732,4 & 9,4 \\
\hline ККП-2 & 0,38 & 0,35 & 0,14 & 0,22 & 0,05 & 2,67 & 817,7 & 71,5 \\
\hline ККП-3 & 0,45 & 0,41 & 0,16 & 0,30 & 0,05 & 2,83 & 838,8 & 73,9 \\
\hline ККП-4 & 0,38 & 0,35 & 0,13 & 0,15 & 0,01 & 2,62 & 608,5 & 15,9 \\
\hline ККП-5 & 0,18 & 0,16 & 0,06 & 0,05 & 0,01 & 1,76 & 244,5 & 6,1 \\
\hline ККП-6 & 0,21 & 0,18 & 0,06 & 0,06 & 0,01 & 1,85 & 257,7 & 7,1 \\
\hline УA-H* & 0,07 & 0,06 & 0,01 & 0 & 0,05 & 1,13 & 256,9 & 61,4 \\
\hline
\end{tabular}

Примечание. * - образец сравнения, ** витамин $\mathrm{B}_{12}$.

с образцом сравнения (табл. 3). Для образцов ККП-5 и ККП-6 наблюдаемый факт может быть обусловлен низким содержанием в их структуре мезопор размером 2,0-5,88 нм и отсутствием мезопор $>7,39$ нм. В структуре УА-Н было выявлено наличие крупных мезопор шириной $\geq 5,00$ нм $\left(5,09,5,87\right.$ и 7,47 нм и более), объем которых составляет $0,04 \mathrm{~cm}^{3} / \Gamma$, что способствует эффективной сорбции данного маркерного вещества [7].

Лучшие значения сорбции МС демонстрируют сорбенты на основе карбонизатов из коры пихты, полученных при температурах от 300 до $500{ }^{\circ} \mathrm{C}$. Данные табл. 3 показывают, что они содержат в своей структуре наибольшие объемы пор, доступных для молекул МС, по сравнению с другими сорбентами из коры пихты. В сочетании с наибольшими объемами мезопор размера 2,0-2,95 нм это обеспечивает высокую сорбцию данного маркерного вещества. Как и в случае с йодом, максимальная сорбция МС наблюдается для сорбента ККП-3. По сорбции МС этот образец превосходит образец сравнения в 3,2 раза.

Наибольшую сорбцию витамина $\mathrm{B}_{12}$ демонстрируют углеродные сорбенты КП-3, ККП2 и ККП-3. Два последних образца характеризуются наибольшим объемом пор 1,48-1,86 нм, доступных молекулам маркера, и мезопор 2,00-2,95 нм, способных выполнять транспортную функцию (табл. 3). Очевидно, сочетание таких пор в их структуре способствует высокой сорбции витамина $\mathrm{B}_{12}$. Образец КП-3 характеризуется меньшими объемами пор вышеуказанных размеров по сравнению с ККП-2 и ККП-3, но по сорбции $\mathrm{B}_{12}$ превосходит их в 1,9 раза. Отметим, что при одинаковом объеме мезопор 3,18-5,88 нм в структуре КП-3 присутствует мезопора $\geq 9,31$ нм. Можно предположить, что именно эти поры обеспечивают более эффективную сорбцию витамина $\mathrm{B}_{12}$, что согласуется с результатами работы [7], показывающими, что высокая сорбция витамина $\mathrm{B}_{12}$ для УА-Н обусловлена наличием в его структуре крупных мезопор шириной более 5,09 нм. 
Полученные данные показывают (табл. 3), что сорбент ККП-3 сочетает высокую сорбционную емкость в отношении йода, МС и витамина $\mathrm{B}_{12}$ и превосходит образец сравнения УА-Н, который применяют в качестве энтеросорбента.

Для оценки возможности применения ККП-3 в аналогичных целях была изучена кинетика сорбции йода, МС и витамина $\mathrm{B}_{12}$ в сравнении с УА-Н. Приведенные на рис. 3 данные показывают, что сорбция йода на ККП-3 протекает более интенсивно по сравнению с УА-Н - сорбционное равновесие устанавливается в 2 раза быстрее (в течение 30 мин), а по значению равновесной сорбции он уступает сорбенту из коры пихты в 1,5 раза (рис. 3).

Константы скорости сорбции, рассчитанные по модели псевдопервого порядка (уравнение 1), равны 0,168 и 0,053 мин ${ }^{-1}$ для ККП-3 и УА-Н соответственно. Очевидно, высокие значения константы скорости и равновесной сорбции йода для ККП-3 обусловлены наличием и количеством микро- и мезопор шириной $0,73-1,86$ и 2,0-2,95 нм в его структуре.

ККП-3 более интенсивно сорбирует и МС по сравнению с УА-Н (рис. 4) - сорбционное равновесие достигается через 45 мин и 10 ч соответственно при константах скорости сорбции МС для ККП-3 и УА-Н 0,095 и 0,009 мин ${ }^{-1}$ соответственно. Очевидно, более высокие значения

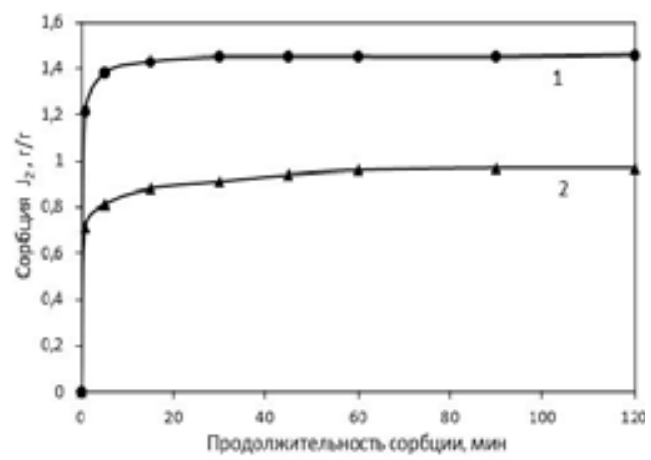

Рис. 3. Кинетика сорбции йода $\left(\mathrm{J}_{2}\right)$ на углеродном сорбенте из коры пихты (1) и активном угле УА-Н (2) Fig. 3. Sorption kinetic of iodine $\left(\mathrm{J}_{2}\right)$ on carbon sorbent from abies bark (1) and active coal $\mathrm{YA}-\mathrm{H}(2)$

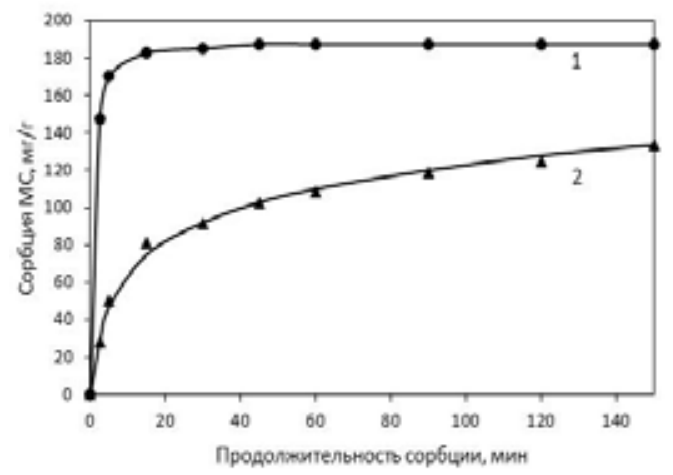

Рис. 4. Кинетика сорбции метиленового синего (МС) на углеродном сорбенте из коры пихты (1) и активном угле УА-Н (2)

Fig. 4. Sorption kinetic of methylene blue (MC)on carbon sorbent from abies bark (1) and active coal YA-H (2) 

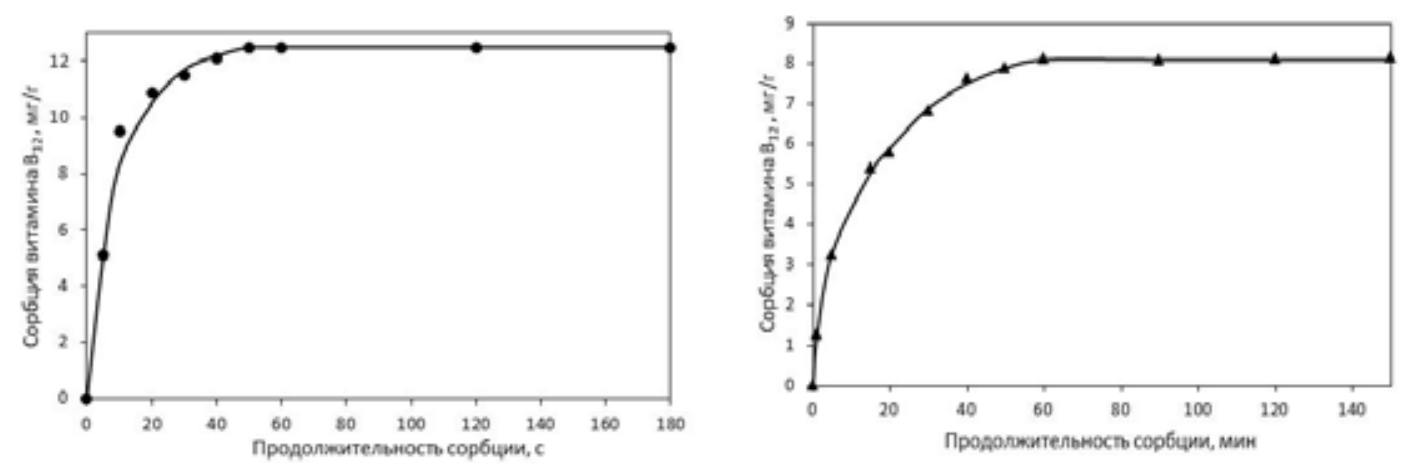

Рис. 5. Кинетика сорбции витамина $\mathrm{B}_{12}$ на углеродном сорбенте из коры пихты (а) и активном угле УА-Н (б)

Fig. 5. Sorption kinetic of vitamin $\mathrm{B}_{12}$ on carbon sorbent from abies bark (a) and active coal $\mathrm{YA}-\mathrm{H}$ (b)

константы скорости и равновесной сорбции МС для ККП-3 обусловлены присутствием в его структуре микро- и мезопор $0,86-1,86$ и 2,0 - 2,95 нм по сравнению с УА-Н.

В большей степени структурные различия ККП-3 и УА-Н влияют на кинетику сорбции витамина $\mathrm{B}_{12}$. Рис. $5 a$ показывает, что сорбция этого маркера на ККП-3 протекает наиболее интенсивно в сравнении с йодом и МС (константа скорости сорбции 4,371 мин ${ }^{-1}$ ), а сорбционное равновесие устанавливается в течение 60 с, тогда как для УА-Н (рис. 5б) равновесие достигается в течение 60 мин при константе скорости сорбции 0,068 мин $^{-1}$, что может быть связано с присутствием в структуре ККП-3 мезопор размером 2,00-5,88 нм.

\section{Заключение}

Изучено влияние соотношения коры пихты и КОН на формирование пористой структуры углеродных сорбентов. Определено, что максимальным значением площади удельной поверхности $\left(1391,5 \mathrm{~m}^{2} / \Gamma\right)$ и объема пор $\left(0,81 \mathrm{~cm}^{3} / \Gamma\right)$ обладает образец, полученный при соотношении кора : щелочь, равном 1:3. Установлено, что предварительная карбонизация коры пихты способствует развитию пористой структуры углеродных сорбентов. Максимальное значение площади удельной поверхности $\left(2431,8 \mathrm{~m}^{2} / \Gamma\right)$ и объема пор $\left(1,23 \mathrm{~cm}^{3} / \Gamma\right)$ достигается при использовании в качестве основы карбонизата, полученного из коры при $400{ }^{\circ} \mathrm{C}$.

Выявлена зависимость сорбции йода, метиленового синего и витамина $\mathrm{B}_{12}$ углеродными сорбентами из коры пихты от объема и размера пор. Показано, что емкость исследованных сорбентов по йоду коррелирует с содержанием в их структуре микропор шириной 0,73-1,86 нм, а по метиленовому синему зависит от микропор шириной $0,86-1,86$ и мезопор 2,0-2,95 нм. Сорбция витамина $\mathrm{B}_{12}$ углеродными сорбентами из коры пихты определяется содержанием в их структуре мезопор шириной 2,00-5,88 нм.

Установлено, что углеродный сорбент на основе карбонизата коры пихты, полученного при $400{ }^{\circ} \mathrm{C}$, сочетает высокие значения сорбционной емкости и скорости сорбции изученных маркеров. Определено, что этот сорбент значительно превосходит образец сравнения УА-Н по скорости сорбции йода, метиленового синего и витамина $\mathrm{B}_{12}$ (в 3,1, 10,5 и 64,5 раза соответственно). Изучение свойств при условиях, принятых для тестирования энтеросорбентов, по-

$$
-431-
$$


казало, что данный углеродный сорбент превосходит промышленный активированный уголь медицинского назначения по сорбционной емкости йода и витамина $\mathrm{B}_{12}$ в 1,5 раза, а по сорбции $\mathrm{MC}-$ в 1,7 раза.

\section{Список литературы}

1. Кузнецов Б.Н., Чесноков Н.В., Иванов И.П., Веприкова Е.В., Иванченко Н.М. Методы получения пористых материалов из лигнина и древесной коры (обзор). Журнал Сибирского федерального университета. Химия. 2015. Т. 8(2). С 232-255. [KuznetsovB.N., Chesnokov N.V., Ivanov I.P., Veprikova E.V., Ivanchenko N.M. Methodsof porous materials obtaining from lignin and wood bark Review). Journal of Siberian federal University. Chemistry 2015. Vol. 8(2). P. 232-255 (In Russ.)]

2. Zoltan Pasztory, Ildiko Ronyecz Mohacsine, Galina Gorbacheva, Zoltan Borcsok. The utilization of tree bark. BioResources 2016. Vol.11(3). P. 7859-7888.

3. Морозов А.С., Бессонов И.В., Нуждина А.И., Писарев В.М. Сорбенты для экстракорпорального удаления токсических веществ и молекул с нежелательной биологической активностью (обзор). Общая реаниматология. 2016. T.12(6). C. 82-107 [Morozov A.S., Bessonov I.V., Nuzhdina A.V., Pisarev V.M. Sorbents for extracorporal removal of toxic substances and molecules with adverse biological activity (Review). General Reanimatology. 2016. Vol. 12(6). P.82-107 (In Russ.)]

4. Исмаилова М.Г., Гутникова А.Р., Исмаилова П.Л. ЭнтеросорбентАУ-К и изучение его фармакологической активности. Вестник фармации. 2010. Т.48(2). С. 44-49 [Ismailov M.G., Gytnikova A.R., Ismailova P.L. Enterosorbent AY-Kand study of himpharmacological activity. Bulletin of Pharmacy 2010. Vol.48(2). P.44-49 (In Russ.)]

5. Патент РФ 2377179. Углеродный адсорбент, способ получения и установка для его осуществления / Мухин В.М., Жуков Д.С., Зубова И.Д., Чебыкин В.В., Чумаков Д.С., Соловьев C.M., Курганов Р.П.; 27.12.2009 [Patent 2377179 RU. Muxin V.M., Gukov D.S., Zubov I.D., Chebykin V.V., Chumakov D.S., Solovev S.M., Kurganov R.P. Carbonadsorbent, method of its preparations and installation for him obtaining. Publ. Date 27.12.2009 (In Russ.)]

6. Фарберова Е.А., Олонцев В.Ф., Тингаева Е.А. Исследование условий получения активных углей медицинского назначения из косточек плодов. Бутлеровские сообщения. 2016. Т. 47(8). C. 73-79 [Farberova E.A., Olontsev V.F., Tingaeva E.A. Investigation of the conditions for obtaining active carbons medical supplies from seed fruit. Butlerov communications 2016. Vol. 47(8). P. 73-79 (In Russ.)]

7. Веприкова Е.В., Иванов И.П., Чесноков Н. В., Кузнецов Б.Н. Влияние пористой структуры углеродных сорбентов из лигнина древесины пихты на сорбцию органических веществ различной природы. Журнал Сибирского федерального университета. Химия. 2018. Т. 11(4). С 488-499 [Veprikova E.V., Ivanov I.P., Chesnokov N.V., Kuznetsov B.N. Effect of aporous structure of the carbons sorbents from Abies wood lidnine on sorption of the organic substances of different nature. Journal of Siberian federal University. Chemistry 2018. Vol. 11(4). P. $488-499$ (In Russ.)]

8. Жен Х.Я., Ю А.М., Ма К.А. Влияние характеристик пор на электрохимическую емкость активированных углей. Электрохимия. 2012. Т. 48(12). С. 1294-1302 [Zheng H.J., Yu A.M., Ма K.A. Effect of pores characteristics on the electrochemical capacity of active coals. Electrochemistry 2012. Vol. 48(12). P. 1294-1302 (In Russ.)] 
9. Jiahui Zhang, Wenbo Zhang, Yue Zhang. Pore structure characteristics of activated carbon fibers derived from Poplar bark liquefaction and their use for adsorption of $\mathrm{Cu}$ (II). BioResources 2018. Vol.10(1). P. 566-574.

10. Mohammed Danish, Rokiah Hashim, M.N. Mohamad Ibrahim, Mohd Rafatullah. Tanweer Ahmad. Otham Sulaiman. Characterization of Acacia Mangium wood based activated carbons prepared in presence of basic activating agents. BioResources 2011. Vol.6(3). P. 3019-3033.

11. Virpi Siipola, Tarja Tamminen, Anssi Kalli, Riikka Lahti, Henrik Romar, Kimmo Rasa, Riikka Keskinen, Jari Hyvaluoma, Markus Hannuba, Hanne Wikberg. Effects of biomass type, carbonization process and activated method on the properties of bio-based activated carbons. BioResources 2018. Vol. 13(3). P. 5976-6002.

12. Иванов И.П., Микова Н.М., Лутошкин М.А., Чесноков Н.В., Кузнецов Б.Н. Изучение строения и свойств нанопористых углеродных материалов, полученных термощелочной активацией лигнинов древесины пихты.. Журнал Сибирского федерального университета. Химия. 2017. T. 10(3). C 390-400 [Ivanov I.P., Mikova N.M., Lutoshkin M.A., Chesnokov N.V., Kuznetsov B.N. The study of structure and properties of nanoporous carbon materials obtained by alkaline thermal activation of lignin of Fir wood. Journal of Siberian federal University. Chemistry 2017. Vol. 10(3). P. 390-400. (In Russ.)]

13. Scherdel C., Reichenauer G., Wiener M. Relationship between pore volumes and surface areas derived from the evaluation of $\mathrm{N}_{2}$-sorption data by DR-, BET- and t-plot. Microporous and Mesoporous Materials. 2010. Vol. 132(3). P. 572-575.

14. Lozano-Castello, D., Suarez-Garsia, F., Cazorla-Amoroz, D., Linares-Solano, A. Porous texture of carbons, in Carbons for Electrochemical Energy Storage Systems. CRC Press - Taylor and Francis Group. Boca Raton-New York: 2002. P. 115-162.

15. ISO 9277:2010-09 (E). Determination of the specific surface area of solids by gas adsorption BET method.

16. Landers J., Gor G. Yu., Neimark A.V. Density functional theory methods for characterization of porous materials. Colloids and Surfaces. A: Physicochemical and Engineering Aspects 2013. Vol. 437. P. 3-32.

17. Markelov D.A., Nitsak O.V., Gerashenko T.T. Comparative study of the adsorption activity of medicinal sorbents. Pharmaceutical Chemistry Journal 2008. Vol. 42(7). P. 405-408.

18. Lijuan Wang. Jian Li. Removal of Methylene Blue from Aqueous Solution by Adsorption onto Crofton Weed Stalk. BioResources 2013. Vol.8(2). P. 2521-2536.

19. Морозова А.А., Лыга Л.К., Ермоленко И.Н. О роли микро- и мезопор волокнистых активных углей в сорбции веществ маркеров из водных сред. Журнал прикладной химии. 1989. № 12. C. 2777-2781.[Morozova A.A., Lyga L.K., Ermolenko I.N. About rule of micro- and mezopores fiber active carbon in sorption of marker substances from water medium. Journal of Applied Chemistry 1989. No. 12. P. 2777-2781 (In Russ.)]

20. Yao Chen. Synthesis, characterization and mechanistic studies of Biomolecules @ mesoMOFs. URL: Http://scholarcommons.ust.edu/etd/5199 (22.05.2018). 